\title{
Quantification and Perspective in Relativist Semantics
}

\author{
Peter Lasersohn \\ University of Illinois \\ version: $6 / 27 / 2008$
}

\begin{abstract}
1.0. Introduction. A common feature of recent relativist semantic analyses is that they treat sentences as expressing contents which are true or false not only relative to a possible world, but also to some other parameter such as an individual, perspective, epistemic state, or standard of taste (Egan et al. 2005; Kölbel 2002; 2004a; 2004b; Lasersohn 2005; MacFarlane 2007a; Richard 2004; Stephenson 2007). While MacFarlane (2005a) has argued that an appeal to parameters other than worlds is not by itself enough to make an analysis relativist, many of the uses to which relativist semantic theories have been put obviously depend on the use of such parameters, and much of the interest in such theories comes from the fact that they treat the truth values of sentence contents as dependent on non-standard parameters.
\end{abstract}

The use of such parameters raises interesting questions for the relation between syntax and semantics - questions which parallel, to some extent, the issues pertaining to the debate about "unarticulated constituents" (Carston 1988; Recanati 2002; Stanley 2000, among many others). If a definite truth value can be assigned to a sentence content only if some particular value for one of these parameters is supplied, must that value be the denotation of some syntactic element of the sentence? Or is it reasonable to treat such parameters purely as indices, with no syntactic correlates?

The question is not quite the same as that raised in the unarticulated constituent debate. There, the issue is how the content (presumably, a proposition) expressed by an assertion is determined - by a syntactically driven compositional procedure, or in part by a pragmatic process of "completion"? But the issue in a relativist theory is not one of how this content is determined, but of how, once determined, it is assigned a truth value. ${ }^{1}$

In Lasersohn (2005), I gave a relativist analysis of "predicates of personal taste," such as fun and tasty, which indexed the denotations of such predicates not only to possible worlds, but also to individuals. To support this analysis, I argued that intuitively correct interpretations could not be

${ }^{1}$ I hesitate somewhat to describe the issue in terms of how the proposition expressed by an assertion is assigned a truth value, because many people take the term proposition as implying, by definition, that all ambiguity, vagueness, indexicality, and other parameters have been resolved, so that a definite truth value can be assigned. Sentence contents will not meet that description in a relativist theory. But if we take the term proposition instead for whatever serves as the content of a declarative sentence in context, or for the object of an attitude, etc., then it may be more reasonable to put the issue in terms of how propositions are assigned truth values. Kölbel (2002) and MacFarlane (2005a) are explicit in using the term proposition for contents whose truth value varies with some parameter. 
obtained by treating these predicates instead as having a hidden argument, interpreted as an indexical pronoun or as a quantified variable. I illustrated the analysis with a small formal fragment in which these predicates did not have any kind of hidden argument, so that the relativization was handled entirely at the level of indices, with no syntactic correlate.

Since the appearance of that paper, Stephenson (2007) has proposed an analysis - otherwise very similar to that of Lasersohn (2005) — which treats these predicates as having a hidden argument place, which may be tied to the individual index in a systematic way; Glanzberg (2007) has argued that a non-relativist analysis (with no extra indices) can be made feasible by properly taking into account the "experiencer" argument of predicates of personal taste; and Stojanovic (2007) has argued that the use of an individual index is semantically equivalent to using an implicit argument, hence that relativist analyses like those in Lasersohn (2005) or Kölbel (2002) are semantically equivalent to the contextual analyses they were intended to replace. Cappelen and Hawthorne (to appear) have argued against a relativist analysis, making crucial use of examples in which a putative hidden argument place in predicates of personal taste is filled by a quantified variable. There thus appears to be considerable disagreement about the utility and significance of using an implicit argument as opposed to an index. The present paper is intended to clarify some of the issues involved, and provide some arguments for an analysis that does not make use of syntactically represented implicit arguments for predicates of personal taste.

1.1. Faultless disagreement. The primary argument in favor of relativist semantic analyses comes from the phenomenon of "faultless disagreement" (Kölbel 2004a). ${ }^{2}$ For example, if John asserts "This licorice is tasty" and Mary asserts "This licorice is not tasty" (referring to the same piece of licorice) we take them to be disagreeing - even contradicting - each other. At the same time, there does not seem to be any matter of fact on which the disagreement turns. Both John and Mary may be fully and accurately informed about the flavor of the licorice, yet still disagree. In this respect, predicates like tasty contrast with predicates like contain sugar: If John asserts that the licorice contains sugar, and Mary asserts that it doesn't, one of them must be making a factual error (or lying), and factual information will be enough to resolve the disagreement.

As Cappelen and Hawthorne (to appear) point out, there are at least two senses to words like agree or disagree, which we must distinguish to understand properly the arguments for and against relativist semantic theories. In one sense, disagree means roughly "to engage in a dispute" - that is, it refers to a particular kind of interactive activity, in which people argue, debate, or negotiate with each other. But in another sense, two people may be said to disagree if they hold mutually contradictory beliefs, regardless of whether they engage each other in a dispute over these beliefs. In this sense, disagreement is a state, not an activity, and people may disagree

${ }^{2}$ In Lasersohn (to appear) I claim there is additional evidence from factive predicates and from de se readings associated with verbs like consider. However, these arguments really only distinguish between a relativist analysis and one which used a hidden indexical pronoun; they do not show that a relativist analysis has an advantage over other possible approaches, such as a "non-indexical contextualist" analysis (MacFarlane 2007b; to appear b). 
without interacting or even being aware of each other's existence.

The recent literature on relativism has often made use of example dialogs in which people argue with each other over some issue for which it is claimed that people may faultlessly disagree. Because of this, the impression may exist that such disputes are the primary phenomenon relativist semantic theories are intended to account for, and that "faultless disagreement" is disagreement in the first sense - an activity people engage in together. But this is a mistake. The issue is not why people engage in any particular form of behavior - a question whose answer will go far beyond semantics in any case - but how people can be in a state of disagreement if there is no matter of fact on which the disagreement turns.

The relativist answer to this is simple: If there is no matter of fact as to whether $P$, then $P$ can be true relative to one person and false relative to another. For example This licorice is tasty may be true relative to John and false relative to Mary. So if John believes $P$ and Mary believes not $P$, they each believe something which is true relative to themselves, and neither makes an error of fact, even though their beliefs contradict each other. The details of how to work this idea out more explicitly vary somewhat from author to author; see Kölbel (2004a), MacFarlane (2007a) for philosophical discussion of the nature of the disagreement, Lasersohn (2005) for a more technical treatment of the associated semantics.

1.2. What are predicates of personal taste? Faultless disagreement has been claimed to arise with statements expressing personal taste (Lasersohn 2005; to appear); moral and aesthetic statements more generally (Kölbel 2002; 2004a); scalar adjectives (Richard 2004); epistemic expressions, including modal verbs, probability statements and the verb know (Egan et al. 2005; Kölbel 2002; 2005b; to appear a); future contingents (MacFarlane 2003); and probably other sorts of expression as well. In this paper, I concentrate on predicates of personal taste, since these seem to me to be the examples with which a relativist treatment has the strongest intuitive basis.

In Lasersohn (2005), I did not give an explicit definition of predicates of personal taste, relying instead on readers' intuitive understanding of what was meant. Although I briefly considered whether there might be some linguistic "test" by which predicates of personal taste could be reliably identified, no such tests were formulated, and I suggested that the classification might have to be made more on philosophical than linguistic grounds.

I still know of no clear test by which predicates of personal taste may be identified. Nonetheless, it seems that some further clarification is in order, particularly as issues of taste relate to scalarity. As Glanzberg (2007) stresses, predicates of personal taste are often gradable adjectives. ${ }^{3}$. For example, an activity can be more fun or less fun; a dish can be very tasty, or not so much. We

${ }^{3}$ The reasons for Glanzberg's emphasis on this fact are not completely clear to me, since scalarity per se plays very little role in his arguments against relativism or in favor of contextualism. It should also be noted that some predicates which express personal taste are not adjectives at all, but verbs: e.g. suck, rock as in That movie sucks or That movie rocks. 
may assume, with Glanzberg, a fairly standard picture of the semantics of scalar predicates: Such predicates are associated semantically with a scale — an ordered set of "degrees." The meaning of the adjective must somehow associate individuals with degrees on the scale. Moreover, for a definite truth value to be assigned, a "cut-off" point on the scale must be specified, with the adjective applying truthfully to individuals which are assigned values above the cut-off point.

With scalar predicates in general, it appears that speakers may faultlessly disagree because they take the cut-off point to be in different positions on the scale (Richard 2004). Thus, John and Mary may disagree whether Bill is rich, even if they both know exactly how much money Bill has, and what the relevant comparison class is, just because they employ different standards about how rich a member of that class has to be to count as rich. As scalar expressions, predicates of personal taste may give rise to faultless disagreement in the same way: John and Mary may be in complete agreement as to the degree of fun produced by engaging in some activity (going bowling, for example), yet disagree whether that degree is high enough for the activity to qualify as fun. But this kind of disagreement is due to scalarity, and has little to do specifically with taste.

What seems crucial for disagreements over taste is not the location of the cut-off point, but the assignment of degrees. Different people may assign markedly different degrees of fun or tastiness to the same items, and may differ radically in the relative order of these items on the fun or tastiness scale; but no objective "matter of fact" would seem to select any one of these assignments or orderings as the correct one. John and Mary may disagree whether skydiving is fun, not because they both realize it is fun to degree $d$ and differ as to whether $d$ is sufficiently high to count as fun, but because John (who enjoys a good thrill) assigns it a high degree of fun, while Mary (who is terrified of falling) does the opposite. (See Figure 1.) 
I would like to limit the term predicates of personal taste to those predicates which allow this kind of interpersonal variation in the assignment of degrees ${ }^{4}$; and disagreement about taste to

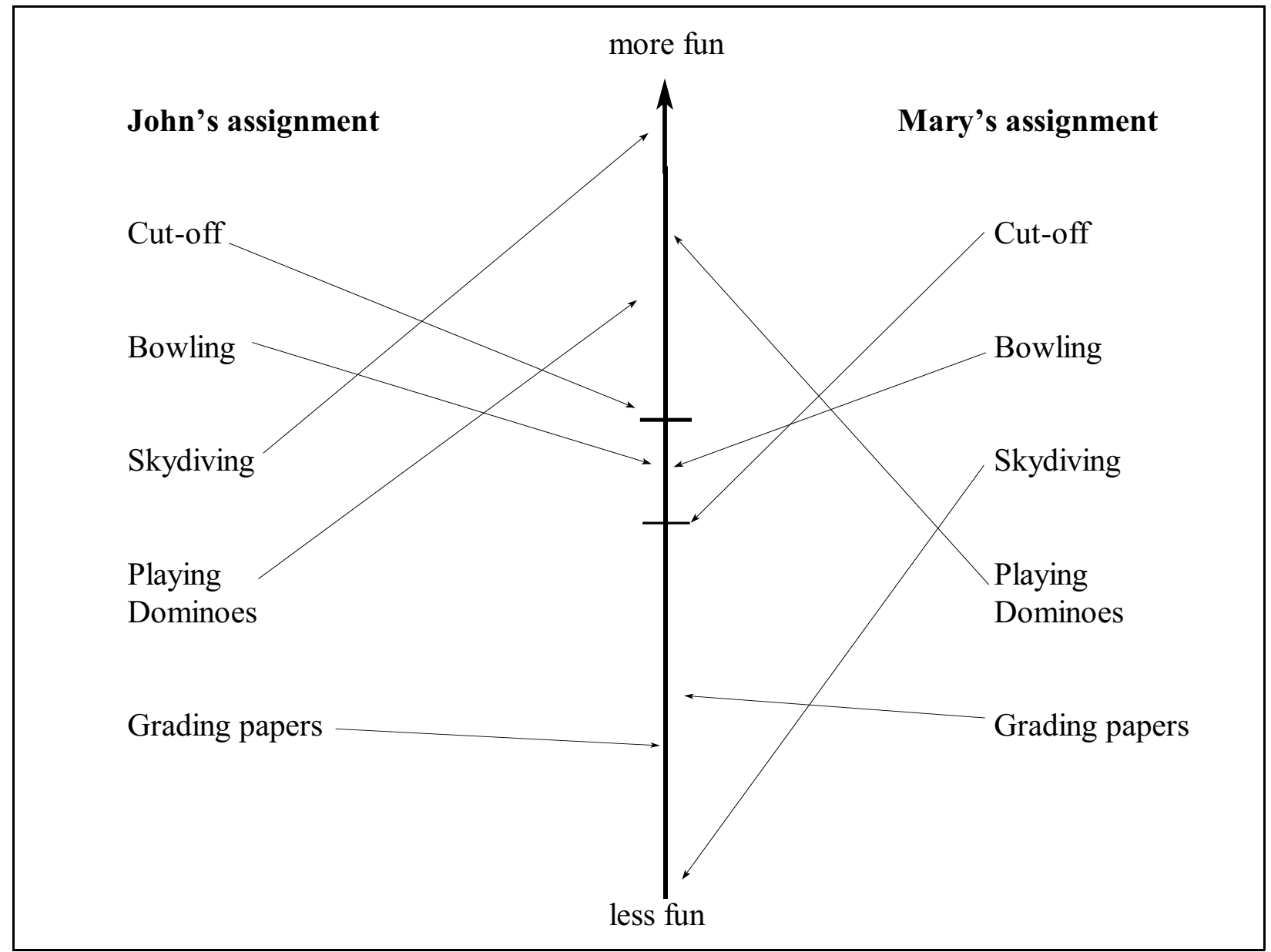

Figure 1: John and Mary agree that playing dominoes is fun and grading papers is not fun; they disagree about whether skydiving is fun and about whether bowling is fun - but for different reasons.

disagreements based on this kind of interpersonal variation. This gives, I think, a somewhat narrower class of predicates than some other authors' use of the term. Cappelen and Hawthorne (to appear), for example, take filling and spicy to be predicates of personal taste; but while people

${ }^{4}$ I don't intend this as a definition, since taste also clearly involves some notion of affect or preference, and because we have not yet properly taken into account how this interpersonal variation relates to semantic content or truth evaluation. Note that ordinary predicates of spatial distance like near and far also allow interpersonal variation in the assignment of degrees; but they do not give rise to faultless disagreement and would certainly not be considered predicates of personal taste. 
may disagree whether a particular dish is filling or spicy (and perhaps this disagreement is faultless), it seems to me that this disagreement is primarily due to variation in where to place the cut-off point, and not because people differ substantially in the relative order in which they would rank dishes according to the degree to which they are filling or spicy. ${ }^{5}$ I will set such predicates aside in this paper, and leave to another occasion the question of just how similarly they should be treated to predicates of personal taste.

2.0. A simple relativist semantics. I will assume in this paper that interpersonal variation in the assignment of degrees associated with predicates of personal taste produces a corresponding interpersonal variation in truth values of sentences containing them. ${ }^{6}$ The issues to be considered are whether this variation in truth value is due to some syntactically present (but phonologically and orthographically "hidden") argument, or instead to a syntactically unrepresented parameter or index; and in either case, how the value of this argument or parameter relates to semantic content and to truth evaluation.

I find such issues easier to work through in the context of a specific set of syntactic and semantic rules, so this section will present a "toy" language, with rules for interpretation. After it is in place, we can consider different hypotheses about the source of the interpersonal variation in truth value exhibited by sentences containing predicates of personal taste. We will also make some modifications and additions to the system later in the paper.

The system to be presented is similar that of Lasersohn (2005; to appear), but expanded to include quantification. The earlier system was based directly on the logic for demonstratives presented in Kaplan (1989), and followed Kaplan's presentation closely (though it did not treat predicates of personal taste in the same way as Kaplan treated demonstrative and indexical pronouns). In the present paper, the relation of the analysis to Kaplan's theory of indexicality is of less immediate concern, so we will not stick quite so close to Kaplan; but the analysis is still broadly in the same framework.

The language is very simple, but constructed to mimic certain features of natural language syntax. The lexicon is as follows:

Basic expressions:

${ }^{5}$ Note that for a certain kind of spiciness (piquancy), we even have a scientific measure: the Scoville Scale, developed by Wilbur Scoville in 1912. Of course individuals also vary in the degree to which they find spicy or filling food to be appealing, but this is an entirely separate matter from the applicability of the predicates spicy and filling themselves.

${ }^{6}$ Several alternative lines of analysis which do not make this assumption are considered in Lasersohn (2005). 

a. $\quad$ Proper names: John, Mary, Bill, The Blue Streak ${ }^{7}$
b. "Overt" pronouns: I, you, pro $_{1}$, pro $_{2}$, pro $_{3}, \ldots$
c. "Covert" pronouns: $\operatorname{pro}_{1}, \operatorname{pro}_{2}$, pro $_{3}, \ldots$
d. Intransitive verbs: is-fun, is-tasty, contains-sugar, is-six-feet-tall
e. Transitive verbs: ate, rode, be
f. Ditransitive verbs: gave, sent
g. Common nouns: man, woman, roller-coaster, ride, dish, licorice-stick
h. Determiners: the, every, some

Proper names and pronouns (overt and covert) will together be called "terms." The indexed pronouns pro $_{1}$, pro $_{2}$, pro $_{3}, \ldots$ do the service of the English third person pronouns he, she, it; we use "pro" in place of these to avoid having to deal with gender agreement. The covert pronouns $p r \theta_{1}, p r \theta_{2}, p r \theta_{3}, \ldots$ serve as hidden indexicals, and also correspond to the "traces" left by Quantifier Raising and similar movement rules in modern syntactic theory. ${ }^{8}$

The syntax includes the following rules:

\section{Formation rules:}

a. If $\alpha$ is a term and $\beta$ is an intransitive verb, then $[\alpha \beta]$ is a sentence.

b. If $\alpha$ is a term and $\beta$ is a transitive verb, then $[\beta \alpha]$ is an intransitive verb.

c. If $\alpha$ is a term and $\beta$ is a ditransitive verb, then $[\beta \alpha]$ is a transitive verb.

d. If $\alpha$ is a term and $\beta$ is an intransitive verb, then $[\beta$ for $\alpha]$ is an intransitive verb.

e. If $\varphi$ and $\psi$ are sentences, then $\neg \varphi,[\varphi \& \psi]$, and $[\varphi \vee \psi]$ are sentences.

f. If $\alpha$ is a common noun and $\delta$ is a determiner, then $[\delta \alpha]$ is a quantifier.

g. If $\varphi$ is a sentence containing at least one occurrence of $\operatorname{pr}_{n}$, then $\lambda n \varphi$ is a sentence abstract.

h. If $\alpha$ is a quantifier and $\sigma$ is a sentence abstract, then $[\alpha \sigma]$ is a sentence.

i. If $\alpha$ is a common noun and $\sigma$ is a sentence abstract, then [ $\alpha$ that $\sigma]$ is a common noun.

We interpret relative to models:

A model is a 5-tuple $\langle W, U, C, F, \mathbf{c}\rangle$, where:

a. $\quad W$ is a non-empty set (of "worlds")

b. $\quad U$ is a non-empty set (of "individuals")

c. $\quad C$ is a non-empty set (of "contexts")

${ }^{7}$ The Blue Streak is an old wooden roller coaster at the Cedar Point Amusement Park near Sandusky, Ohio.

${ }^{8}$ We ignore many complexities of English syntax, such as pronoun case, the distinction between reflexive and non-reflexive pronouns, conditions on coindexation, subject-verb agreement, and rules limiting the distribution of covert pronouns. 

d. $\quad F$ is a function assigning values to proper names, intransitive verbs, transitive verbs, and common nouns as given below
e. $\quad \mathbf{c} \in C$

Contexts may be identified with 5-tuples of the form $\left\langle\mathrm{A}_{c}, \mathrm{Y}_{c}, \mathrm{D}_{c}, \mathrm{~W}_{c}, \mathrm{~J}_{c}\right\rangle$, where:
a. $\quad \mathrm{A}_{c} \in U$ (the "agent", or speaker/author, of $c$ )
b. $\quad Y_{c} \in U$ (the addressee of $c$ )
c. $\quad \mathrm{D}_{c}$ is a finite sequence of elements of $U$ (the "indicated individuals" of $c$; these will serve as the values of demonstratively interpreted pronouns.)
d. $\quad \mathrm{W}_{c} \in W$ (the world of $c$ )
e. $\quad \mathrm{J}_{c} \in U$ (the "judge" of $c$ - that is, the individual on whom the truth value of sentences containing predicates of personal taste depends)

We do not regard contexts in the formal sense defined here as corresponding one-one with concrete situations in which a sentence is used; rather, each situation of use corresponds to as many formal contexts as there are individuals, with each individual serving as judge in a separate formal context. This means that the judge is undetermined by the situation in which a sentence is used - a feature which will be important in accounting for the intuition that "matters of fact" fall short of fixing the truth values of statements of personal taste.

$F$ should map each triple of a world, individual, and proper name, intransitive verb, transitive verb ditransitive verb, or common noun to a value as follows:
a. If $\alpha$ is a proper name, then $F(w, u, \alpha) \in U$.
b. If $\alpha$ is an intransitive verb or common noun, then $F(w, u, \alpha) \subseteq U$.
c. If $\alpha$ is a transitive verb, then $F(w, u, \alpha) \subseteq U \times U$.
d. If $\alpha$ is a ditransitive verb, then $F(w, u, \alpha) \subseteq U \times U \times U$.

We consider fun and tasty to be "subjective" expressions, whose denotation is a matter of personal taste and therefore varies from individual to individual. All other expressions assigned values by $F$ are "objective," and subject to the following constraint:

(6) If $\alpha$ is objective, then for all $w, u, u^{\prime}: F(w, u, \alpha)=F\left(w, u^{\prime}, \alpha\right)$.

Proper names should also denote rigidly across worlds:

(7) If $\alpha$ is a proper name, then for all $w, w^{\prime}, u: F(w, u, \alpha)=F\left(w^{\prime}, u, \alpha\right)$.

An appropriate assignment of values to variables for a model $M=\langle W, U, C, F, \mathbf{c}\rangle$ is an (infinite) sequence of elements of $U$.

We write $\llbracket \alpha \rrbracket^{M, c, w, u, g}$ for the denotation of $\alpha$ relative to model $M$, context $c$, world $w$, individual $u$, 
and assignment $g$, defined for basic expressions as follows:

(8) a. If $\alpha$ is a proper name, intransitive verb, transitive verb, or common noun, then $\llbracket \alpha \rrbracket^{M, c, w, u, g}=F(w, u, \alpha)$.

b. $\llbracket I \rrbracket^{M, c, w, u, g}=\mathrm{A}_{c}$. ( $I$ is the first person pronoun, and always denotes the agent of its context.)

c. $\llbracket y o u \rrbracket^{M, c, w, u, g}=\mathrm{Y}_{c}$. (You is the second person pronoun.)

d. $\quad \llbracket p r o_{n} \rrbracket^{M, c, w, u, g}=\llbracket p r \theta_{n} \rrbracket^{M, c, w, u}=$ the $n^{\text {th }}$ element of $g$.

e. $\llbracket b e \rrbracket^{M, c, w, u, g}=\{\langle x, x\rangle \mid x \in U\}$

f. $\quad \llbracket$ the $\rrbracket^{M, c, w, u, g}=\{\langle X, Y\rangle \subseteq \operatorname{pow}(U) \times \operatorname{pow}(U) \mid \exists x[X=\{x\} \& x \in Y]\}$

g. $\quad \llbracket$ every $\rrbracket^{M, c, w, u, g}=\{\langle X, Y\rangle \subseteq \operatorname{pow}(U) \times \operatorname{pow}(U) \mid X \subseteq Y\}$

h. $\llbracket$ some $\rrbracket^{M, c, w, u, g}=\{\langle X, Y\rangle \subseteq \operatorname{pow}(U) \times \operatorname{pow}(U) \mid X \cap Y \neq \varnothing\}$

Note that all basic expressions other than pronouns have the same denotation relative to every context: $\llbracket \alpha \rrbracket^{M, c, w, u, g}=\llbracket \alpha \rrbracket^{M, c^{\prime}, w, u, g}$ for all $c, c^{\prime}$.

Sentences will denote truth values, with predication working in the expected way:

(9) a. If $\alpha$ is a term and $\beta$ is an intransitive verb, then

$$
\begin{aligned}
& \llbracket[\alpha \beta] \rrbracket^{M, c, w, u, g}=1 \text { if } \llbracket \alpha \rrbracket^{M, c, w, u, g} \in \llbracket \beta \rrbracket^{M, c, w, u, g} \\
& \llbracket[\alpha \beta] \rrbracket^{M, c, w, u, g}=0 \text { if } \llbracket \alpha \rrbracket^{M, c, w, u, g} \notin \llbracket \beta \rrbracket^{M, c, w, u, g}
\end{aligned}
$$

b. If $\alpha$ is a term and $\beta$ is a transitive verb, then

$$
\llbracket[\beta \alpha] \rrbracket^{M, c, w, u, g}=\left\{u \in U \mid\left\langle u, \llbracket \alpha \rrbracket^{M, c, w, u, g}\right\rangle \in \llbracket \beta \rrbracket^{M, c, w, u, g}\right\}
$$

c. If $\alpha$ is a term and $\beta$ is a ditransitive verb, then

$$
\llbracket[\beta \alpha] \rrbracket^{M, c, w, u, g}=\left\{\left\langle u, u^{\prime}\right\rangle \in U \times U \mid\left\langle u, u^{\prime}, \llbracket \alpha \rrbracket^{M, c, w, u, g}\right\rangle \in \llbracket \beta \rrbracket^{M, c, w, u, g}\right\}
$$

Modification of a predicate with a for-phrase makes it objective; tasty for Mary will denote, relative to any individual, those things which tasty denotes relative to Mary:

(10) If $\alpha$ is a term and $\beta$ is an intransitive verb, then $\llbracket[\beta$ for $\alpha] \rrbracket^{M, c, w, u, g}=\llbracket \beta \rrbracket^{M, c, w, a, g}$, where $a=$ $\llbracket \alpha \rrbracket^{M, c, w, u, g}$.

Connectives work in the usual way: 
(11) If $\varphi, \psi$ are sentences, then

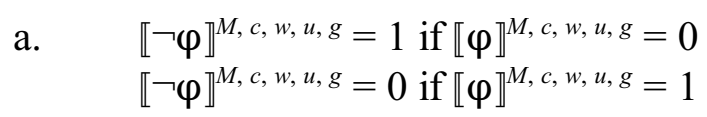

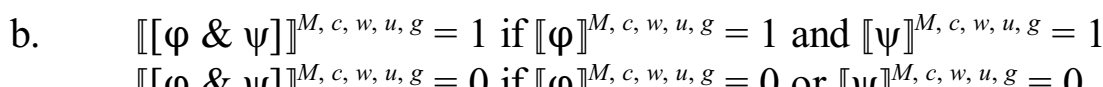 $\llbracket[\varphi \& \psi] \rrbracket^{M, c, w, u, g}=0$ if $\llbracket \varphi \rrbracket^{M, c, w, u, g}=0$ or $\llbracket \psi \rrbracket^{M, c, w, u, g}=0$
c. $\quad \llbracket[\varphi \vee \psi] \rrbracket^{M, c, w, u, g}=1$ if $\llbracket \varphi \rrbracket^{M, c, w, u, g}=1$ or $\llbracket \psi \rrbracket^{M, c, w, u, g}=1$ $\llbracket[\varphi \vee \psi] \rrbracket^{M, c, w, u, g}=1$ if $\llbracket \varphi \rrbracket^{M, c, w, u, g}=0$ and $\llbracket \psi \rrbracket^{M, c, w, u, g}=0$

The $\lambda$-binder also works in the expected way:

(12) $\llbracket \lambda n \varphi \rrbracket^{M, c, w, u, g}=\left\{x \in U \mid \llbracket \varphi \rrbracket^{M, c, w, u, g[x / n]}=1\right\}$, where $g[x / n]$ is that sequence in which $x$ is the $n^{\text {th }}$ element and which agrees with $g$ in all other positions.

Quantifiers denote sets of sets of individuals, as in Barwise and Cooper (1981):

(13) If $\delta$ is a determiner and $\alpha$ is a common noun, then $\llbracket[\delta \alpha] \rrbracket^{M, c, w, u, g}=\left\{Y \subseteq U \mid\left\langle\llbracket \alpha \rrbracket^{M, c, w, u, g}\right.\right.$, $\left.Y\rangle \in \llbracket \delta \rrbracket^{M, c, w, u, g}\right\}$.

Quantification is straightforward:

(14) If $\alpha$ is a quantifier and $\sigma$ is a sentence abstract, then

$$
\begin{aligned}
& \llbracket[\alpha \sigma] \rrbracket^{M, c, w, u, g}=1 \text { if } \llbracket \sigma \rrbracket^{M, c, w, u, g} \in \llbracket \alpha \rrbracket^{M, c, w, u, g} \\
& \llbracket[\alpha \sigma] \rrbracket^{M, c, w, u, g}=0 \text { if } \llbracket \sigma \rrbracket^{M, c, w, u, g} \notin \llbracket \alpha \rrbracket^{M, c, w, u, g}
\end{aligned}
$$

Sentence abstracts also serve as relative clauses, which intersectively modify their common nouns:

(15) If $\alpha$ is a common noun and $\sigma$ is a sentence abstract, then

$$
\llbracket[\alpha \text { that } \sigma] \rrbracket^{M, c, w, u, g}=\llbracket \alpha \rrbracket^{M, c, w, u, g} \cap \llbracket \sigma \rrbracket^{M, c, w, u, g}
$$

Pronouns which are not bound will be interpreted demonstratively. Technically, this means we may drop the dependence of denotation on $g$ by letting pronouns take their values from $D_{c}$. In the case of sentences, this gives us something similar to a standard Tarskian definition of truth via satisfaction, but with the quantification over sequences restricted to just those sequences agreeing with $D_{\mathrm{c}}:^{9}$

(16) Where $\varphi$ is a sentence:

$$
\llbracket \varphi \rrbracket^{M, c, w, u}=1 \text { if } \llbracket \varphi \rrbracket^{M, c, w, u, g}=1 \text { for all } g \text { agreeing with } D_{\mathrm{c}}
$$

${ }^{9}$ Where $D_{\mathrm{c}}$ is an $n$-place sequence, $g$ agrees with $D_{\mathrm{c}}$ iff for all $i(1 \leq i \leq n)$, the $i^{\text {th }}$ element of $D_{\mathrm{c}}$ is identical to the $i^{\text {th }}$ element of $g$. 
$\llbracket \varphi \rrbracket^{M, c, w, u}=0$ if $\llbracket \varphi \rrbracket^{M, c, w, u, g}=0$ for all $g$ agreeing with $D_{\mathrm{c}}$

(undefined otherwise)

But the pattern in (16) can be subsumed under a more general rule dropping the relativization to assignments for expressions of all types:

If $\llbracket \alpha \rrbracket^{M, c, w, u, g}=\llbracket \alpha \rrbracket^{M, c, w, u, g^{\prime}}$ for all $g, g^{\prime}$ agreeing with $D_{\mathrm{c}}$, then $\llbracket \alpha \rrbracket^{M, c, w, u}=\llbracket \alpha \rrbracket^{M, c, w, u, g}$, for any $g$ agreeing with $D_{\mathrm{c}}$ (undefined otherwise).

The following examples illustrate how sentences in English may be rendered into our toy language:
a. $\quad$ The Blue Streak is fun $\Rightarrow$ [The-Blue-Streak is-fun $]$
b. It is fun $\Rightarrow\left[\right.$ pro $_{1}$ is-fun $]$
c. $\quad$ The Blue Streak is fun for me $\Rightarrow$ [The-Blue-Streak [is-fun for I]]
d. Every roller coaster is fun $\Rightarrow$ [[every roller-coaster $] \lambda 1\left[\right.$ pro $_{1}$ is-fun $\left.]\right]$
e. John rode every roller coaster $\Rightarrow\left[[\right.$ every roller-coaster $] \lambda 1\left[\right.$ John [rode pro $\left.\left.\left.{ }_{1}\right]\right]\right]$
f. Every licorice stick that contains sugar is tasty $\Rightarrow$
[[every [licorice-stick that $\lambda 2\left[\right.$ pro $_{2}$ contains-sugar $\left.\left.]\right]\right] \lambda 1\left[\right.$ pro $_{1}$ is-tasty]

g. Every man rode some roller coaster that is fun for him $\Rightarrow$

$\left[[\right.$ every man $] \lambda 1\left[\left[\right.\right.$ some [roller-coaster that $\lambda 2\left[\right.$ pro $_{2}\left[\right.$ is-fun $\left[\right.$ for pro $\left.\left.\left.\left.\left.{ }_{1}\right]\right]\right]\right]\right]$ $\lambda 3\left[\operatorname{pro}_{1}\left[\right.\right.$ rode pro $\left.\left.\left.\left.{ }_{3}\right]\right]\right]\right]$

The content of an expression $\alpha$ in a given context $c$ (relative to $M, g$ ), notated $\llbracket \alpha \rrbracket^{M, c, g}$, will be that function which maps any world $w$ and individual $u$ onto the denotation of $\alpha$ relative to $M, c, w, u$, $g$; that is, $\llbracket \alpha \rrbracket^{M, c, g}(w, u)=\llbracket \alpha \rrbracket^{M, c, w, u, g}$.

As with denotation, we may drop the relativization of content to $g$, assigning free pronouns their values according to $D_{\mathrm{c}}$ :

If $\llbracket \alpha \rrbracket^{M, c, g}=\llbracket \alpha \rrbracket^{M, c, g^{\prime}}$ for all $g, g^{\prime}$ agreeing with $D_{c}$, then $\llbracket \alpha \rrbracket^{M, c}=\llbracket \alpha \rrbracket^{M, c, g}$, for any $g$ agreeing with $D_{\mathrm{c}}$ (undefined otherwise).

We say that a sentence $\varphi$ is true in context $c$ (in $M$ ) iff its content in $c$ (in $M$ ) maps the world and judge of $c$ onto 1 , that is iff $\llbracket \varphi \rrbracket^{M, c}\left(\mathrm{~W}_{\mathrm{c}}, \mathrm{J}_{\mathrm{c}}\right)=1$. Since each model includes a designated context $\mathbf{c}$, we may say that $\varphi$ is true in $M$ iff $\varphi$ is true in $\mathbf{c}$ (in $M$ ).

As in Kaplan (1989), separate notions of entailment, contradiction, etc. may be defined at the level of sentences and at the level of sentence contents. We may say that two sentences $\varphi$ and $\psi$ contradict each other iff there is no $M$, such that $\varphi$ is true in $M$ and $\psi$ is true in $M$. More relevant to our concerns at the moment, however, is contradiction at the level of content: If $p$ and $q$ are two sentence contents (that is, two functions from world-individual pairs to truth values), we say that $p$ and $q$ contradict each other iff there is no world $w$ and no individual $u$ such that $p(w, u)=1$ 
and $q(w, u)=1$.

It should be noted that in this system, as in Kaplan (1989), the pronouns vary in content from context to context, as do sentences containing unbound pronouns. In contrast, sentences containing no unbound pronouns receive the same content in all contexts, even if they contain a subjective predicate: $\llbracket\left[[\right.$ the licorice-stick $] \lambda 1\left[\right.$ pro $_{1}$ is-tasty $\left.]\right] \rrbracket^{M, c}=\llbracket\left[[\right.$ the licorice-stick $] \lambda 1\left[\right.$ pro ${ }_{1}$ istasty] $] \rrbracket^{M, c^{\prime}}$ for all $M, c, c^{\prime}$.

Nonetheless, sentences containing a subjective predicate may vary in truth value from context to context. If two contexts have different judges, i.e. if $\mathrm{J}_{\mathrm{c}} \neq \mathrm{J}_{c^{\prime}}$, it might happen that $\llbracket[[$ the licoricestick $] \lambda 1\left[\right.$ pro $_{1}$ is-tasty $\left.]\right] \rrbracket^{M, c}\left(w, \mathrm{~J}_{\mathrm{c}}\right)=1$ and $\llbracket\left[[\right.$ the licorice-stick $] \lambda 1\left[\right.$ pro $_{1}$ is-tasty $\left.]\right] \rrbracket^{M, c^{\prime}}\left(w, \mathrm{~J}_{c^{\prime}}\right)=0$. Of course then it would also be the case that $\llbracket\left[[\right.$ the licorice-stick $] \lambda 1\left[p r \theta_{1}\right.$ is-tasty $\left.]\right] \rrbracket^{M, c}\left(w, \mathrm{~J}_{\mathrm{c}}\right)=1$ and $\llbracket \neg\left[[\right.$ the licorice-stick $] \lambda 1\left[\right.$ pro $_{1}$ is-tasty $\left.\left.]\right]\right]^{M, c^{\prime}}\left(w, \mathrm{~J}_{c^{\prime}}\right)=1$. That is, the sentence and its negation could both be true (relative to their separate contexts). Despite this fact, $\llbracket[[$ the licorice-stick $] \lambda 1$ $\left[\right.$ pro $_{1}$ is-tasty $\left.]\right] \rrbracket^{M, c}$ and $\llbracket \neg\left[[\right.$ the licorice-stick $] \lambda 1\left[\right.$ pro $_{1}$ is-tasty $\left.]\right] \rrbracket^{M, c^{\prime}}$ will always contradict each other, even when $c$ and $c^{\prime}$ are distinct. This allows us an explanation of faultless disagreement: two sentences can express mutually contradictory contents, yet both be true relative to different individuals.

2.1. Relativism, assessment and stance. What makes this system "relativist"? Different authors use this term in different ways. As I understand it, there are two crucial features of the system just outlined which make this term appropriate. First, sentences may vary in truth value without a corresponding variation in content. Second, this variation depends on some parameter whose value is not fixed by the situation in which a sentence is used.

These criteria are equivalent, as far as I can tell, to the claim that sentences may be assigned contents whose truth values depend not just on the "context of use" but also on the "context of assessment" (MacFarlane 2003; 2005a). We treat the context of use as fully determined by the situation in which the sentence is used; if truth values vary independently of this situation, we regard them as at least partly dependent on a separate context determined by the situation in which the sentence is assessed for truth or falsity. Accordingly, we may think of each context $c$ in the system presented above as consisting of a context of use $c_{\mathrm{U}}$, supplying $\mathrm{A}_{c}, \mathrm{Y}_{c}, \mathrm{D}_{c}$ and $\mathrm{W}_{c}$, and a potentially separate context of assessment $c_{\mathrm{A}}$, supplying $\mathrm{J}_{c}$.

A few words of caution are in order regarding this terminology. ${ }^{10}$ Even if we draw a distinction between a context of use and a context of assessment, contexts in the formal sense may sometimes be only somewhat indirectly related to the concrete situations in which sentences are used or assessed. It may easily happen that an author produces a written message containing tense or temporal indexicals such as now, for example, intending it to be interpreted relative to a context specifying the relevant time as the time at which the intended recipient reads the message.

${ }^{10}$ This caution is my own; I am not sure if it would be endorsed by John MacFarlane, to whom the terminology is due. 
(See especially Predelli 2005 for this kind of example.) Even if the relevant time is not the time at which the message is composed, however, it is still determined by the intentions of the communicating agent — that is, it is determined in the situation in which the sentence is used, not the situation in which it is received or assessed. ${ }^{11}$ So we regard the time which serves as the anchor for tense and for temporal adverbials as supplied by the context of use, even if it is not the time when the utterance itself takes place.

By the same token, we may regard the "judge" parameter as specified by the context of assessment, without requiring that the judge actually be the person performing a truth assessment of a sentence - or even that the judge be present in the situation where the sentence is assessed at all. Just as the intentions of the author of a written message can fix the context of use to one whose time is different from the actual time when the message is composed, the intentions of a person assessing a sentence for truth or falsity may fix the context of assessment to one whose judge is some other person.

This happens, for example, when a predicates like fun is ascribed to a particular event, as in Mary rode the roller coaster yesterday; it was fun. An event of Mary riding the roller coaster on one specific occasion would not normally be fun for anyone but Mary; nonetheless someone else might assess a claim that this event had been fun. It would be pragmatically pointless for a person who was uninvolved in the event to assess such a claim relative to himself or herself; instead, the normal practice in such cases is to assess it relative to a pragmatically salient person who was involved. That is, the truth assessor may adopt an exocentric stance, as opposed to the more usual autocentric stance in which the one assesses relative to a context with oneself specified as the judge. ${ }^{12}$ While an autocentric stance is more typical in truth assessment, the claim that the contents of sentences expressing personal taste are assessment-sensistive does not commit us to the simple view that such sentences are always assessed to be true according to whether they are true relative to the assessor.

3.0. Relativism, contextualism and indices. Stojanovic (2007) uses a basic result from modal logic to argue that a system similar to that presented in Section 2 above is semantically equivalent to a more conventional contextualist system. The argument takes the form of an intertranslatability proof between a language using an individual index (in addition to a possible worlds index) and a language which instead uses a designated variable, serving as an argument to predicates of personal taste. Thus, a sentence like The licorice is tasty might be represented as tasty(the-licorice) in the first language, but tasty(the-licorice, $x_{\mathrm{T}}$ ) in the second, where $x_{\mathrm{T}}$ is the

${ }^{11}$ Note that an unintended recipient who found the message and assessed it relative to a time other than the one intended would clearly be misunderstanding the message.

${ }^{12}$ I prefer autocentric and exocentric to the more established terms egocentric and allocentric (used, for example, in psychological studies of spatial cognition), because allocentric is sometimes used in a sense closer to what I have called acentric, and because egocentric carries negative connotations in non-technical usage. 
designated variable.

The proof is simple and need only be briefly summarized here: For each language, we define a class of structures (where each structure includes sets from which the values of the indices are drawn, and an interpretation function of the usual sort) and models (where each model includes a structure, particular values for the indices, and an assignment of values to variables). Then we can easily define a translation function $T$ mapping each model for one of the languages onto a corresponding model for the other language, and each formula in the first language onto a corresponding sentence in the second language, so that for any $M, \varphi: \varphi$ is true in $M$ iff $T(\varphi)$ is true in $T(M)$.

If we think of pronouns as like variables, it would now appear that a language like that of Section 2 , using an individual index but no hidden argument to predicates of personal taste, could be perfectly translated into a language in which predicates of personal taste have a hidden pronoun argument, but there is no individual index. The choice between the two analyses would then seem to be arbitrary, at least as far as semantics is concerned.

But really, this proof establishes intertranslatability only in a relatively broad sense. This becomes apparent as soon as one notices that Stojanovic nowhere gives an explicit definition of semantic content, or an explanation of how content relates to context. If, following Kaplan, we assume that the values of pronouns are fixed as part of the assignment of contents to expressions in context, and not as part of the assignment of truth values to contents, then it is apparent that a formula like tasty(the-licorice, $x_{\mathrm{T}}$ ) will receive different contents relative to assignments of different values to $x_{\mathrm{T}}$, while a variable-free formula like tasty(the-licorice) will receive the same content relative to all assignments of values to variables. In this case, the translation function will not respect sameness and different of semantic content - hardly a perfect translation! ${ }^{13}$

On the other hand, if we assume that values of pronouns are fixed in the assignment of truth values to sentence contents, rather than the assignment of contents to expressions in context, then we must regard the content of a formula like tasty(the-licorice, $x_{\mathrm{T}}$ ) as true or false only relative to an assignment of values to variables $g$. In this case, $g$ functions as an index on content - much like possible world index or (more to the point) the individual index of the system presented above in Section 2 - and we haven't really eliminated the non-standard index in favor of an implicit argument after all.

In brief, showing that two sentences have the same distribution of truth values across a set of models or indices does not show they are equivalent in content, if the mapping from indices to truth values proceeds Kaplan-style in two steps, and content is defined with reference to the level

${ }^{13}$ The translation is about as good as the equivalence between I am hungry and The one who is speaking now is hungry; if one of these sentences is true at a given context, the other one will be too; but they express truth-conditionally distinct contents (since the content of $I$ is "stable" in the sense of Kaplan 1989, and the content of the one who is speaking now is not). 
between the steps. Since the debate between relativism and contextualism turns partly on the issue of which parameters get fixed in which step, we cannot ignore this issue in comparing the two approaches.

I conclude that the use of non-standard indices is not semantically equivalent to the use of implicit pronoun arguments without such indices.

3.1. Indexicalism and disagreement. Given that the use of a non-standard index does make some semantic difference, we are now faced with the decision whether to make use of such an index or not. To say that such indices are needed really amounts to a claim that at least some sentence contents are true or false only relative to some non-standard parameter; to say they are not needed amounts to a denial of this claim. Since we are assuming that sentences expressing personal taste $d o$ vary in truth value from person to person, denying that their contents vary in this way entails that the same sentence may be assigned different contents relative to different people. This is exactly what one would expect if such sentences contain hidden indexical pronouns, and it is natural on this view to suppose that the variation comes from different possible values that can be assigned to this pronoun.

I have already argued at length elsewhere against the idea that personal taste sentences can be treated this way (Lasersohn 2005; to appear). I will not repeat these arguments in detail here, but the central problem is that this analysis does not explain the phenomenon of faultless disagreement. If John says that roller coaster are fun, and Mary says that roller coasters are not fun, we can treat them as both saying something true by claiming that they use different values for the hidden pronoun; but then their claims do not contradict each other, and we have no reason to view their assertions as expressing disagreement. If we say that they use the same value for the pronoun, we can explain the intuition of disagreement very straightforwardly, but it will not be "faultless," since one or the other assertion must be false.

Glanzberg (2007) favors exactly this kind of theory, claiming that pragmatic context fixes the value of an "experiencer" argument to predicates of personal taste, in essentially the same way as it fixes the value of a pronoun. To support this idea, he suggests that in a situation where John says "The chili is tasty" and Mary says "The chili is not tasty," but they are in different contexts — for example, in separate rooms "musing about food" — we get "[n]o clear judgment about disagreement without more information" about the value of the experiencer argument. In particular, "They might not disagree, for instance, if each is just talking about their own private tastes..."

My intuitions differ, as long as we are considering disagreement in the stative sense, discussed in Section 1.1, above. If John believes the chili is tasty and Mary believes it is not tasty, they disagree; and this does not require that they share a context, or even that they are aware of each other's existence. And while it is unfortunate that this issue comes down to a matter of raw intuition, I should point out that this intuition is acknowledged even by some anti-relativist writers (Cappelen and Hawthorne to appear, Ch. 4). An anti-relativist may claim, perhaps, that the 
intuition is rooted in a mistaken view of the truth conditions of such sentences; but it is, in any case, a widely shared intuition, for which we owe some kind of explanation.

Note that this intuition is also problematic for an analysis which claims that when John says "The chili is tasty" and Mary says "The chili is not tasty," their statements do not contradict each other, but produce a sense of disagreement because John and Mary are in conflict about what the context is: a context which fixes the value of the indexical in such a way as to make John's statement true, or one which fixes it in such as way as to make Mary's statement true. In Lasersohn (2005) I argued against such an analysis based on considerations which were purely internal to a Kaplan-style semantic theory; but a more serious problem is the fact that people may disagree over matters of taste without any notion of shared context. John and Mary's mutual friend might very naturally report them as disagreeing, for example, even if they made their statements on different occasions and were unaware of each other's claims.

Perhaps these considerations do not close the door on an indexical analysis completely; but the indexicalist needs some way of accounting for our intuitions of disagreement without relying on a presumption of shared context - and if we take these intuitions at face value, as indicative of authentic disagreement over the truth values of claims like "The chili is tasty" or "The chili is not tasty," such a strategy seems highly problematic.

\subsection{Pronoun ambiguity. Even if one acknowledges the need for a non-standard index in} accounting for faultless disagreement, the possibility remains open that predicates of personal taste sometimes have a hidden indexical argument. It might be that sentences containing such predicates are systematically ambiguous between a relativist reading and an indexical reading, the latter appearing when the indexical pronoun is present. This approach acknowledges the need for a relativist semantics, but allows that a more traditional contextualist semantics also plays a role in interpreting predicates of personal taste.

I briefly but inconclusively considered such an analysis in Section 7.1 of Lasersohn (2005). Stephenson (2007) develops a similar idea in more detail, ${ }^{14}$ and argues (pp. 95-97) that it eliminates the theoretical need for exocentric truth assessment. For example, one could claim that in Mary rode the roller coaster yesterday; it was fun, the predicate fun has a hidden pronoun argument set to Mary, so the final clause expresses a content which is true if the ride was fun for Mary, and false if it wasn't - rather than claiming (as I did in Section 5, above) that Mary's tastes are relevant only because of the choice of context of assessment, and not because of anything in the semantic content of the sentence.

${ }^{14}$ There are some differences between the approach considered in Lasersohn (2005) and the one developed in Stephenson (2007): I treated the indexical use as basic, and derived the relativistic interpretation via a diagonalization operation like that in Stalnaker (1979); Stephenson simply assumes there are two different pronouns with different interpretations. The choice between these analyses need not concern us here. 
This view makes a good deal of intuitive sense, and it must be acknowledged that a theory which treats selection of the relevant individual as a matter of truth assessment rather than content faces a challenge: If circumstances require all conversational participants to assess exocentrically, there is a strong tendency for them to "coordinate" their stances and all assess relative to the same individual. For example it is natural in our current example for all participants to assess it was fun relative to Mary. Nothing in the idea of an exocentric stance or context of assessment obviously predicts this effect.

Moreover, Stephenson suggests, an analysis which treats such examples indexically rather than relativistically has an advantage in that it predicts that faultless disagreement will never arise with examples in which the speaker intends an evaluation relative to some third party. She offers the following example:

(20) Sam: This tuna is tasty.

Sue: No it isn't! It's not tasty at all!

Sam and Sue might be disagreeing whether the tuna is tasty for their cat; or they might be disagreeing based on their own tastes. However, Stephenson suggests, there can be no disagreement in the mixed case, where Sam means that the tuna is tasty for the cat, and Sue is expressing her own taste in her response. If we read the example this way, Sue's utterance sounds infelicitous, since it takes the form of a disagreement without actually disagreeing.

Certainly it would be odd for Sue to argue with Sam based on her own tastes if he were clearly assessing his own assertion relative to the cat. But I do not believe that it is correct to say that faultless disagreement is impossible whenever the speaker assesses relative to a third party. Suppose John and Mary are discussing how their young son Bill liked the amusement park. Their obnoxious neighbor Fred overhears and butts in:

Mary: How did Bill like the rides?

John: Well, the merry-go-round was fun, but the water slide was kind of scary.

Fred: Oh, it was not! Your kid is just a weenie!

Here Fred disagrees with the claim that the water slide was scary, even though John clearly intends it to be assessed relative to Bill. ${ }^{15}$ We get no sense in this example that Fred has misunderstood who John was referring to, and no sense that he believes that Bill actually enjoyed the water slide.

\footnotetext{
${ }^{15}$ The status of scary as a predicate of personal taste is open to debate. But analogous dialogs can be constructed with fun:
}

Mary: How does Bill like school?

John: Well, he doesn't go in much for sports, but the science fair was fun.

Fred: Oh, it was not! Your kid's just a geek! 
The difference between examples (20) and (21), I think, is not that the speakers contradict each other in one case but not the other, but merely that it is easier in (21) than in (20) to imagine a plausible pragmatic purpose to expressing the disagreement. Fred might be the sort of person who tries to make his own children look good by pointing out the shortcomings of other people's children, for example; or perhaps he has some vested interest in making sure that the water slide is seen as an appropriate ride for children Bill's age. But what would Mary have to gain by pointing out that her tastes conflict with the cat's? To the extent that we can imagine a plausible reason, (20) will begin to sound less anomalous, even in the mixed case. I conclude that examples like (20) do not provide support for the idea that predicates of personal taste have an argument place which is sometimes filled by a hidden indexical argument.

\subsection{The hidden argument and Principle B. Stephenson (2007; to appear) gives a second} argument in favor of the claim that predicates of personal taste have a hidden argument place, based on Principle B of Chomsky's (1981) Binding Theory. This principle prohibits non-reflexive pronouns from having antecedents in the same local domain - roughly, the same clause. Stephenson offers this argument as evidence not only for the possibility of a hidden indexical pronoun, but also for the presence in syntactic representation of a special, relativistically interpreted pronoun $\mathrm{PRO}_{\mathrm{J}}$.

By the rule in (22), $\mathrm{PRO}_{\mathrm{J}}$ is assigned a value fixed to the individual index. This has the effect that in any context $c$, it will denote the judge of $c$ :

$$
\llbracket \mathrm{PRO}_{\mathrm{J}} \rrbracket^{M, c, w, u, g}=u
$$

The claim is that predicates of personal taste normally make take either $\mathrm{PRO}_{\mathrm{J}}$ or a hidden indexical pronoun as an argument, producing an ambiguity between relativistic and indexical readings.

Next, Stephenson suggests that the hidden "PRO" subject of the infinitival complement of verbs like want and try is actually $\mathrm{PRO}_{\mathrm{J}}$. That is, a sentence like John wants to sing would have a logical representation analogous to (23):

want (John, $\left.\operatorname{sing}\left(\mathrm{PRO}_{\mathrm{J}}\right)\right)$

Combined with some elementary and plausible assumptions about attitude verbs, this allows for a simple and interesting explanation for the fact that the hidden subject of such infinitival clauses is obligatorily interpreted de se, as Stephenson shows in some detail. ${ }^{16}$

Now, assuming that $\mathrm{PRO}_{\mathrm{J}}$ is a non-reflexive pronoun, by Principle B it should not be possible for it to have an antecedent in the same local domain. This means that in infinitival complements to

\footnotetext{
${ }^{16}$ See also Lasersohn (to appear) for discussion of de se readings for relativistically interpreted complement clauses.
} 
verbs like want and try, $\mathrm{PRO}_{\mathrm{J}}$ cannot fill the hidden argument place of predicates of personal taste, because then it would be anteceded by the $\mathrm{PRO}_{\mathrm{J}}$ hidden subject, which is in the same clause (the infinitival complement clause). Thus, representations like (24)b., for (24)a., should be ruled out:
a. Sue wants to be entertaining.
b. want(Sue, entertaining $\left(\mathrm{PRO}_{\mathrm{J}}, \mathrm{PRO}_{\mathrm{J}}\right)$ )

Here, entertaining is assumed to be a predicate of personal taste; the first $\mathrm{PRO}_{\mathrm{J}}$ is the subject of the infinitival clause to be entertaining, and the second $\mathrm{PRO}_{\mathrm{J}}$ is filling the putative hidden argument place of predicates of personal taste.

Stephenson thus derives a prediction that predicates of personal taste cannot take $\mathrm{PRO}_{\mathrm{J}}$ as their second argument in infinitival complement clauses with hidden subjects.

Because $\mathrm{PRO}_{\mathrm{J}}$ is ruled out in this position, some other pronoun (possibly a covert pronoun) must be used instead. This other pronoun may be interpreted indexically, allowing a reading for (24)a. in which Sue wants to be entertaining for some salient group or individual.

Stephenson claims that this is in fact the observed pattern: (24)a. can only mean that Sue wants to be entertaining to some salient group or individual, and not that she wants to be entertaining to herself. She presents the following scenario and judgments, where '\#' indicates pragmatic anomaly:

(25) [Context: Sue hates spending time alone. When she's with other people, they generally seem to enjoy her company, appreciating her stories and laughing at her jokes, but she just can't ever seem to entertain herself, and wishes that she could.]
a. \# Sue wants to be entertaining.
b. Sue wants to be entertaining to herself.

However, the situation is a little more complicated than one might expect, given just this example. If one examines a broader range of data, the pattern appears to be slightly different from what Stephenson suggests. Let us change the example just slightly:

(26) John tried very hard to be funny. He was always telling jokes — and people usually laughed. But he was never satisfied that he had really succeeded in being funny. He had such a low opinion of other people's senses of humor, and so little confidence in himself, that he attributed their laughter to their unsophistication, and not to any real funniness on his own part. He really wanted to be funny, but could never convince himself that he really was, no matter how people reacted.

This example sounds quite natural to me, but the natural interpretation is not that John wants to 
be funny to his audience, but that he wants to be funny tout court, and judges funniness by his own standards, and not the reaction of others. But this is precisely the reading one should assign to a formula like 'want(John, funny $\left(\mathrm{PRO}_{\mathrm{J}}, \mathrm{PRO}_{\mathrm{J}}\right)$ '.

An important point here is that the judge of a context is the one according to whose tastes an object is evaluated as funny, entertaining, fun, tasty, etc. - and this need not be the individual towards whom jokes or entertainment are directed, or who does the actual tasting, etc. Sentence (25)a. is anomalous, I would suggest, not because a judge-dependent reading is ruled out for predicates of personal taste in infinitival clauses with hidden subjects, but because it means that Sue wants to be entertaining in general - that is, on all those occasions when she tries or hopes to entertain - and not just on those occasions when she is alone trying to amuse herself. But the context is set up in (25) in such a way as to suggest that her frustration is only on the latter sort of occasion, so (25)a. is not a natural expression of what Sue wants in this scenario.

To say that (25)a. means that Sue wants to be entertaining on all those occasions when she tries or hopes to entertain is not to say that it means that she wants to be entertaining on all these occasions according to the standards of the people she is attempting to entertain (though it would be natural for her to want this, and might reasonably be inferred pragmatically). Depending on whether Sue takes an autocentric or exocentric stance, it may be her own tastes that are relevant to the truth of (25)a., or those of some other relevant group or individual; but it is in any case not incompatible with the meaning of the sentence that it is Sue's own tastes that are relevant, even when she is entertaining others.

I conclude that examples like (25)a. do not show Principle B effects, and so do not provide evidence for a hidden pronoun argument to predicates of personal taste.

3.4. The binding argument. A somewhat different argument for a hidden argument for predicates of personal taste comes from quantification. If it is possible to quantify over the individuals whose tastes are relevant to the assessment of personal taste statements, this suggests that there must be a variable serving as an argument for the predicate. For example, if (27) can be interpreted as meaning that each customer $x$ was served a dish that was tasty for $x$ (but not necessarily for the other customers, or the speaker, listeners, etc. ${ }^{17}$ it would seem that tasty must have an argument place for the $x$ :

\section{Every customer was served a tasty dish.}

This argument is reminiscent of that given by Stanley (2000) against "unarticulated constituents"; it seems hard to believe that a variable could be supplied pragmatically, so any variable that is needed must be supplied by syntax.

${ }^{17}$ I have found that a significant number of speakers do not accept this reading; but enough do that some account of it ought to be given. 
In considering this argument, some caution is necessary in the choice of examples. If an attitude verb intervenes between the quantifier and the predicate of personal taste, as in (28), all speakers allow a reading in which each customer $x$ believed his dish was tasty for $x$ :

Every customer believed his dish was tasty.

But this does not show that tasty has a hidden variable argument. For any sentence content (set of world-individual pairs) $p$ and individual $i$, let $p^{i}$ be the sentence content which holds true at any world $w$ and individual $j$ if and only if $p$ holds true at $w$ and $i$, i.e. $p^{i}=\{\langle w, j\rangle \mid\langle w, i\rangle \in p\}$. Intuitively, $p^{i}$ may be read as " $p$ is true for $i$." Now examples like (28) are easily dealt with without a hidden argument for tasty, simply by letting believe denote a relation between individuals and sentence contents, and adopting a general principle that if $i$ believes $p$, then $i$ believes $p^{i}$. (For example, if John believes licorice is tasty, then John also believes licorice is tasty for John.) We may represent (28) essentially as in (29). ${ }^{18}$ Here, tasty has no hidden argument, but we obtain the correct interpretation, with each customer $x$ believing his dish was tasty for $x$ :

$$
\left[[\text { every customer }] \lambda 1\left[\text { pro }_{1}\left[\text { believes }^{\wedge}\left[\left[\text { pro }_{1}{ }^{\prime} \text { s dish }\right] \lambda 2\left[\text { pro }_{2} \text { is-tasty }\right]\right]\right]\right]\right]
$$

In dealing with examples like (27), with no attitude verb, we have several options. Of course one possibility is to posit a hidden variable argument to tasty, but this is by no means our only available technique. Another possibility - though not one I would advocate - is to treat such examples as having a hidden attitude verb, so that (27) means something like "Every customer was served a dish which he believed was tasty." Then we could obtain the correct interpretation for (27) in the same way as for (28). But this approach seems extremely ad hoc and syntactically implausible.

A third option, which I believe is more reasonable, is to quantify directly on the individual index, setting and resetting its value in tandem with the variable introduced by a quantifier. This idea can be easily implemented in our current system by introducing a second sentence-abstract-forming operator, in addition to the $\lambda$-operator defined in (12), above:

(30) a. If $\varphi$ is a sentence containing at least one occurrence of $p r \theta_{n}$, then $\mu n \varphi$ is a sentence abstract.

b. $\quad \llbracket \mu n \varphi \rrbracket^{M, c, w, u, g}=\left\{x \in U \mid \llbracket \varphi \rrbracket^{M, c, w, x, g[x / n]}=1\right\}$

This allows us to represent sentence (31)a. as (31)b., for example:

${ }^{18}$ Obviously, we would need to augment the rules of Section 2 to generate this sentence and interpret it. I will not give the necessary amendments here, except to clarify that the ${ }^{\wedge}$-operator forms a term denoting the content of the sentence it attaches to, i.e. $\llbracket{ }^{\wedge} \varphi \rrbracket^{M, c, w, u}=$ $\llbracket \varphi \rrbracket^{M, c}$. In order to avoid irrelevant distractions, I've made some simplifications to the treatment of belief, particularly as it relates to issues of stance; see Lasersohn (2005; to appear) for more discussion. 
(31) a. Every man rode some ride that is fun.

b. $\quad\left[[\right.$ every man $] \mu 1\left[\left[\right.\right.$ some $\left[\right.$ ride that $\lambda 2\left[\right.$ pro $_{2}$ is-fun $\left.\left.]\right]\right] \lambda 3\left[\right.$ pro $_{1}\left[\right.$ rode pro $\left.\left.\left.\left.{ }_{3}\right]\right]\right]\right]$

It should be evident that (31)b. receives a reading in which each man rode a ride which is fun for him, even though there is no variable corresponding to for him in the syntactic representation. The index itself is "bound," but this is part of our metalanguage, not the object language.

Binding the index in this way does not give us the full expressive power of standard variable binding. If, for example, we were to claim that predicates of personal taste have hidden argument places which can be filled by any of a set of covert pronouns like $\operatorname{pro}_{1}, \operatorname{pro}_{2}, \operatorname{pro}_{3} \ldots$, we should expect to find cases where two of these pronouns both appear free inside the scopes of two different variable-binding operators, each of which binds just one of the pronouns. For example, sentence (32) should have a reading in which the hidden argument for fun is bound to every man, but the hidden argument for tasty is bound by some woman:

$$
\text { Every man gave some woman a fun ride and a tasty dish. }
$$

But in fact, this sentence does not have such a reading. It can be interpreted at least three ways: The speaker might be expressing his or her own opinion that the rides were fun and the dishes were tasty, or claiming that the each man gave a ride that was fun for him and a dish that was tasty for him, or that each woman received a ride that was fun for her and a dish that was fun for her; but the sentence cannot mean that each man gave some woman a ride that was fun for him, and a dish that was tasty for her. ${ }^{19}$

These three readings are derived straightforwardly in a theory with index binding. We may represent them essentially as in (33)a., b. and c.:

a. $\quad\left[[\right.$ every man $] \lambda 1\left[[\right.$ some woman $] \lambda 2\left[\left[\left[\right.\right.\right.$ some $\left[\right.$ ride that $\lambda 3\left[\right.$ pro $_{3}$ is-fun $\left.\left.]\right]\right] \lambda 4\left[\right.$ pro $_{1}$ $\left[\left[\right.\right.$ gave pro $\left._{2}\right]$ pro $\left.\left.\left._{4}\right]\right]\right] \&\left[\left[\right.\right.$ some $\left[\right.$ dish that $\lambda 5\left[\right.$ pro $_{5}$ is-tasty $\left.\left.]\right]\right] \lambda 6\left[\right.$ pro $_{1}\left[\left[\right.\right.$ gave pro $\left.{ }_{2}\right]$ $\left.\left.\left.\left.\left.\left.\operatorname{pro}_{6}\right]\right]\right]\right]\right]\right]$

b. $\quad\left[[\right.$ every man $] \mu 1\left[[\right.$ some woman $] \lambda 2\left[\left[\left[\right.\right.\right.$ some $\left[\right.$ ride that $\lambda 3\left[\right.$ pro $_{3}$ is-fun $\left.\left.]\right]\right] \lambda 4\left[\right.$ pro $_{1}$ $\left[\left[\right.\right.$ gave $\left.\mathrm{pro}_{2}\right]$ pro $\left.\left.\left._{4}\right]\right]\right] \&\left[\left[\right.\right.$ some $\left[\right.$ dish that $\lambda 5\left[\right.$ pro $_{5}$ is-tasty $\left.\left.]\right]\right] \lambda 6\left[\right.$ pro $_{1}\left[\left[\right.\right.$ gave pro $\left.{ }_{2}\right]$ $\left.\left.\left.\left.\left.\left.\operatorname{pro}_{6}\right]\right]\right]\right]\right]\right]$

c. $\quad\left[[\right.$ every man $] \lambda 1\left[[\right.$ some woman $] \mu 2\left[\left[\left[\right.\right.\right.$ some $\left[\right.$ ride that $\lambda 3\left[\right.$ pro $_{3}$ is-fun $\left.\left.]\right]\right] \lambda 4\left[p^{2} \theta_{1}\right.$ $\left[\left[\right.\right.$ gave $\left.\operatorname{pro}_{2}\right]$ pro $\left.\left.\left._{4}\right]\right]\right] \&\left[\left[\right.\right.$ some $\left[\right.$ dish that $\lambda 5\left[\right.$ pro $_{5}$ is-tasty $\left.\left.]\right]\right] \lambda 6\left[\right.$ pro $_{1}\left[\left[\right.\right.$ gave pro $\left.{ }_{2}\right]$ $\left.\left.\left.\left.\left.\left.\operatorname{pro}_{6}\right]\right]\right]\right]\right]\right]$

But the "missing" reading, in which each man gives some woman a ride that was fun for him and a

\footnotetext{
${ }^{19}$ It might also be that the speaker adopts an exocentric stance anchored to some specific group or individual for both tasty and fun, but this has no bearing on our current issue.
} 
dish that was tasty for her, cannot be represented, because we do not have separate variables serving as arguments to fun and to tasty. Instead, we are employing a single, systematic parameter, relative to which all denotations are assigned; and if an operator manipulates this parameter, it will do so for all expressions in its scope.

The intuition behind this pattern can perhaps be expressed this way: In a relativist theory, in order to assess a sentence for truth or falsity, one must adopt a stance — that is, truth assessment is always done from a particular perspective. Operators in the sentence may shift the perspective from which truth assessment is to be done, or quantify over such perspectives; and when they do so, the relevant perspective must be adopted for the entire scope of the operator. Because such operators shift the perspective from which truth is assessed, rather than shifting the denotation of some particular expression like a pronoun, they cannot selectively shift only certain items in their scope.

3.5. Using a designated variable. The considerations of the last section do not quite show that predicates of personal taste do not have syntactically represented hidden pronoun arguments; they only show that they cannot have arguments freely chosen from a set of pronouns similar to $\operatorname{pro}_{1}$, $\operatorname{pro}_{2}, \mathrm{prO}_{3}, \ldots$ If all predicates of personal taste always took the same pronoun as a hidden argument, we would predict that any operator which bound one occurrence of this variable would also bind all other free occurrences in its scope, and the correct range of interpretations for sentences like (32) would fall out. Are there any reasons for preferring an analysis with no hidden argument to one like this, in which all predicates of personal taste take the same, special, designated pronoun as a hidden argument?

In developing this idea, in order to maintain a relativistic interpretation for the pronoun when it is not bound, we should require that its value is set to the individual index. Essentially, this means the pronoun should be Stephenson's $\mathrm{PRO}_{\mathrm{J}}$, defined in (22) above.

Stephenson does not use this pronoun in cases where the hidden argument of predicates of personal taste is bound by a quantifier; instead she assumes that ordinary covert pronouns may also serve as arguments to these predicates. In the analysis currently under discussion, however, $\mathrm{PRO}_{\mathrm{J}}$ would be the only covert pronoun which could fill the hidden argument place of predicates of personal taste. This is compatible with bound readings for $\mathrm{PRO}_{\mathrm{J}}$, if we continue to use indexbinding operators like $\mu$.

I think we are unlikely to find any purely semantic evidence separating this sort of analysis from one using index-binding but no syntactically represented pronoun; the choice between the analyses will have to be made on syntactic grounds.

Syntactic evidence is not hard to find, however. Normally, when a quantifier is assigned scope, it cannot bind pronouns outside its surface c-command domain; doing so produces a crossover 
violation. ${ }^{20}$ For example, sentence (34)a. is not naturally read as (34)b.:

(34) a. His mother loves every man.

b. $\quad(\forall x: \operatorname{man}(x))[x$ 's mother loves $x]$

This same pattern holds with covert pronouns as well as overt ones. The verbs lift, forget and lose, for example, allow a covert pronoun argument, as in (35)a., b. and c..$^{21}$

(35) a. John grabbed the box and lifted.

b. John knew the answer, but forgot.

c. John entered the race, but lost.

But in (36) through (38), the sentences in a. do not admit the readings in b.:

(36) a. The man who lifted put every box on the shelf.

b. $\quad(\forall x: \operatorname{box}(x))[$ the man who lifted $x$ put $x$ on the shelf $]$

(37) a. A student who forgot once knew every answer.

b. $\quad(\forall x$ : answer $(x))[$ a student who forgot $x$ once knew $x]$

(38) a. The runner who lost threw every race.

c. $\quad(\forall x: \operatorname{race}(x))[$ the runner who lost $x$ threw $x]$

But predicates of personal taste can be "crossed over" with no problem. Sentence (39)a., for example, can be understood as (39)b. - a puzzling fact if the $x$ in $\operatorname{tasty}(y, x)$ in (39)b. corresponds to a syntactically represented pronoun:

(39) a. A tasty dish awaited every diner.

${ }^{20}$ There are a few systematic exceptions to this generalization which need not concern us here, mainly involving so-called "psych" verbs: That his mother loves him surprises every man.

${ }^{21}$ It might be thought that these verbs simply have intransitive uses equivalent to "lift something," "forget something," and "lose something," rather than taking covert pronoun arguments. But this is incorrect; it fails to predict the anomaly of (i)a. - c.:

(i) a. ?John lifted, but I don't know what.

b. ?John forgot, but I don't know what.

c. ?John lost, but I don't know what.

Some verbs do have intransitive uses equivalent to existentially quantifying on the direct object argument place, and allow this locution much more naturally: John ate, but I don't know what. See Fillmore (1986) for discussion. 


\section{b. $\quad(\forall x: \operatorname{diner}(x))(\exists y: \operatorname{dish}(y) \& \operatorname{tasty}(y, x))[y$ awaited $x]$}

The correct interpretation can be obtained without positing such a pronoun through the use of index-binding:

$\left[[\right.$ every diner $] \mu 1\left[\left[\right.\right.$ some dish that $\lambda 2\left[\right.$ pro $_{2}$ is-tasty $\left.]\right] \lambda 3\left[\right.$ pro $_{3}\left[\right.$ awaited pro $\left.\left.\left.\left.{ }_{1}\right]\right]\right]\right]$

3.6. Quantification and inference in relativist semantics. Cappelen and Hawthorne (to appear Ch. 4) make an interesting argument against a relativist analysis of predicates of personal taste, based on quantified readings of the putative hidden argument. They consider a relativist eavesdropper, who hears someone reasoning aloud as follows:

(41) Every member of the class of ' 84 will get something tasty at the party.

I am a member of the class of ' 84 .

So, I will get something tasty at the party.

Cappelen and Hawthorne stipulate that the first sentence is to receive a bound reading, so that it means that for each member $x$ of the class of ' $84, x$ will get something tasty which is tasty for $x$ at the party; and also stipulate that the eavesdropper adopts an autocentric stance in assessing the speaker's whole argument. Because the first sentence receives a bound reading, its truth value will not vary from person to person, even in a relativist theory. We may imagine that the eavesdropper accepts the truth of the first two sentences; but if he does not find tasty the thing that the speaker will receive at the party (sushi, let's say), he may still assess the third sentence as false. Since the premises are true but the conclusion is false for the eavesdropper, he will judge the argument to be invalid. "But," say Cappelen and Hawthorne, "it is very strange indeed for anyone to judge the argument invalid!"

Strangeness, like tastiness, is something about which judgments vary. Suppose our eavesdropper is listening for the purpose of gathering information about where he can find tasty food to steal. Before he even hears the speaker of (41), he has made the following plan:

If anyone at the party has something tasty, I will steal it.

Knowing that the speaker of (41) is to receive sushi, the eavesdropper is unlikely to steal it - and hearing the speaker give the argument in (41) is unlikely to make him change his mind or regard his decision as inconsistent with his earlier plans. It is actually not odd or inconsistent at all for someone to accept the premises of (41), but reject the conclusion that the speaker will get something tasty; because we all know that tastes vary from person to person.

Part of our reluctance to view the argument in (41) as invalid, I think, comes from the fact that the speaker does not seem to be making any error in reasoning. But if faultless disagreement is possible, it can only be because different people reach mutually contradictory conclusions without making any errors in reasoning. If we accept the existence of faultless disagreement, we should 
not be surprised to find that the same reasoning leads to a conclusion which is true relative to one person but false relative to another.

This last comment deserves some elaboration, because many readers are apt to worry that if logical validity is relative, then the whole enterprise of logic is in danger of falling apart. I think this is unlikely, though, because it is only a limited and specialized kind of reasoning which allows relativized validity.

Consider logical consequence at the level of sentences, for example. This may be defined analogously to our definition of contradiction for sentences in Section 2, above: $\varphi$ has $\psi$ as a logical consequence iff for all models $M$, if $\varphi$ is true in $M$ then $\psi$ is true in $M$. Since each model includes a designated context, and each context specifies a judge, this definition involves a quantification over judges; $\varphi$ has $\psi$ as a logical consequence only if $\psi$ is true relative to every judge relative to which $\varphi$ is true - there is no possibility that $\varphi$ will have $\psi$ as a logical consequence for some people but not others.

Likewise consider entailment at the level of sentence contents (functions from world-individual pairs to truth values). Analogously to our definition of contradiction for sentence contents, we may say that $p$ entails $q$ iff for all $w, u$, if $p(w, u)=1$ then $q(w, u)=1$. Here also we quantify over the individuals relative to whom the sentence contents are true; there is no possibility that $p$ will entail $q$ for some people but not others.

How, then, can we regard the conclusion of (41) as legitimate for the speaker to draw, but not the eavesdropper? The fact is that logical consequence and entailment as just defined do not exhaust the consequence relations which may be identified in a system like the one set up in Section 2. We may define others, including relativistic ones. Where $u$ is any individual and $p, q$ are sentence contents, let us say that $p u$-entails $q$ iff for all $w$, if $p(w, u)=1$ then $q(w, u)=1$. That is, $p$ $u$-entails $q$ iff whenever $p$ is true for $u, q$ is also true for $u$. The argument in (41) is of this kind: in any world where the premises are true for the speaker, the conclusion will be true for the speaker also; but there may well be worlds where the premises are true for the eavesdropper, without the conclusion also being true for him. ${ }^{22}$

${ }^{22}$ Of course the sentences in (41) are not part of our toy language. For an analogous argument that can be checked against the formalism, consider (i), represented as (ii):

(i) Every man ate a tasty dish.

I am a man.

I ate a tasty dish.

(ii) $\quad\left[[\right.$ every man $] \mu 1\left[\left[\right.\right.$ some dish that $\lambda 2\left[\right.$ pro $_{2}$ is-tasty $\left.]\right] \lambda 3\left[\right.$ pro $_{1}\left[\right.$ ate pro $\left.\left.\left.\left.{ }_{3}\right]\right]\right]\right]$

[[some man] $\lambda 1[$ I [be pro 1$]]$

$\left[\left[\right.\right.$ some dish that $\lambda 1\left[\right.$ pro $_{1}$ is-tasty $\left.]\right] \lambda 2[I[$ ate pro 2$\left.]]\right]$ 
Intuitively, inferences based on $u$-entailment are legitimate in any context where $u$ is the judge. Assuming the speaker and the eavesdropper in (41) both assess the argument autocentrically, this makes the inference legitimate for the speaker, but allows the eavesdropper to accept the premises while rejecting the conclusion. Of course, the eavesdropper may also adopt an exocentric stance, placing himself "in the shoes" of the speaker, and see that the speaker makes no mistake in logic. The reasoning in (41) is not completely unavailable to the eavesdropper, but it gives him no reason to accept the conclusion as applying to himself.

4. Digression on index-binding and unarticulated constituents. I have argued that what appears to be binding of a covert pronominal argument to predicates of personal taste is actually better analyzed as quantification on a non-standard index. The availability of such an analysis suggests that we might apply a similar idea in other cases where semanticists have argued for the existence of covert pronouns, particularly if the primary evidence for the existence of such pronouns is their apparent bindability. Probably the best known such argument is that of Stanley (2000), against the existence of "unarticulated constituents."

Stanley argues that all contextual effects on the truth conditions of sentences must be due to syntactically represented contextually sensitive expressions, and never to purely pragmatic mechanisms with no syntactic correlates. A central part of the argument is that in nearly all cases where some constituent of the proposition expressed by a sentence appears to be provided by the pragmatics, one may find analogous sentences whose interpretation seems to involve a bound variable in place of the pragmatically supplied element. Since it seems implausible to suppose that pragmatic context could provide a variable, it must be represented syntactically. But once this covert syntactic expression is admitted, it seems reasonable to regard the pragmatically supplied constituent as its denotation, rather than as something which contributes to truth conditions noncompositionally, with no syntactic representation.

For example, a number of expressions, such as those expressing distance or orientation (local, distant, left, right, etc.), make some sort of reference to a spatial perspective point, which is often left implicit. For example, in (43), it is left implicit what location the bar is local relative to; but this information is important to the truth conditions of any assertion made using this sentence:

John visited a local bar.

One might suppose the perspective point is provided pragmatically, without serving as the denotation of any element in the syntactic representation of this sentence; but (Stanley's argument goes) examples like (44) make this problematic:

Every reporter visited a local bar.

This sentence has a reading in which each reporter $x$ visits a bar which is local to $x$. It is implausible to suppose that pragmatics could provide a variable, so something in the syntax must be playing the role of $x$. But once we have posited this covert syntactic element, it is natural to 
suppose that it is also present in (43), where it simply denotes the relevant location.

I have a good deal of sympathy with Stanley's position that truth conditions must be determined compositionally from syntactic structure. However, I do not believe the availability of bound readings is sufficient to demonstrate the presence of covert syntactic elements, because of the availability of metalanguage quantification on indices.

We might, for example, add a location index to our system, writing $\llbracket \alpha \rrbracket^{M, c, w, l, u, g}$ for the denotation of $\alpha$ relative to model $M$, context $c$, world $w$, location $l$, individual $u$ and assignment $g$. Now we would regard each context $c$ as providing a perspective point $\mathrm{P}_{c}$, define the content of an expression $\alpha$ (relative to $M, c, g$ ) as that function $\llbracket \alpha \rrbracket^{M, c, g}$ which maps any world $w$, location $l$ and individual $u$ onto $\llbracket \alpha \rrbracket^{M, c, w, l, u, g}$, and let a sentence $\varphi$ be true in $c$ (relative to $\left.M, g\right)$ iff $\llbracket \varphi \rrbracket^{M, c, g}\left(\mathrm{~W}_{c}\right.$, $\left.\mathrm{P}_{c}, \mathrm{~J}_{c}\right)=1 .{ }^{23}$

Local, left, right, etc., do not give rise to faultless disagreement the way predicates of personal taste do, ${ }^{24}$ so probably we should regard the perspective point as determined by the intentions of the speaker, hence as part of the context of use rather than the context of assessment. This makes the analysis of expressions whose denotations vary with $l$ "non-indexical contextualist" rather than relativist.

Next we add a sentence-abstract forming operator $\pi$, which binds the location index in the same way as $\mu$ binds the individual index: ${ }^{25}$

$$
\llbracket \pi n \varphi \rrbracket^{M, c, w, l, u, g}=\left\{x \in U \mid \llbracket \varphi \rrbracket^{M, c, w, L(x), u, g[x / n]}=1\right\} \text {, where } L(x) \text { is the location of } x .
$$

Now (44) can be represented as in (46), with no hidden argument for local: ${ }^{26}$

\footnotetext{
${ }^{23}$ Obviously, we would need to revise our full set of rules; but I forgo spelling out all the details here.

${ }^{24}$ Since local is vague, it may give rise to faultless disagreement based on interpersonal differences about just how close something has to be to count as local; but this is the kind of faultless disagreement which is due to scalarity, not the kind which is due to taste.

${ }^{25}$ We might also consider adding an operator that binds both indices simultaneously.

${ }^{26}$ This analysis is perhaps a little reminiscent of that in Pagin (2005) in that it treats quantified unarticulated constituents by using metalanguage quantification, rather than binding variables in the object language; but our metalanguage quantification, unlike Pagin's, is over ordinary indices rather than contexts. It therefore does not require us to assume that contexts may differ from each other only in the value of a single parameter - a feature which Stanley (2005) argues is problematic, following Lewis (1981).
} 
As with predicates of personal taste, index binding does not give the full expressive power of an analysis in which expressions like local may take any of a series of variables like $p r \theta_{1}, p r \theta_{2}, \ldots$ as a hidden argument. Such an analysis allows a reading for (47) in which each man sends some woman a dish that is local to him, and a movie that is foreign to her; whereas an index binding analysis predicts that local and foreign should both be evaluated relative to the same location, even on the bound reading:

Every man sent some woman a local dish and a foreign movie.

My intuition is that the index binding account makes the correct prediction here.

The same prediction would be made by an analysis that used a hidden argument, but limited the choice of this argument to some specially designated variable. Here again, I think the issue can probably only be decided on a syntactic basis, with crossover as the primary evidence. Stanley (2000) actually uses crossover to argue in favor of a hidden argument to expressions like local; his intuition is that (48)a. cannot be read as (48)b.:

$$
\begin{aligned}
& \text { a. A local bar sponsored every reporter. } \\
& \text { b. } \quad(\forall x: \operatorname{reporter}(x))(\exists y: \operatorname{bar}(y) \& \text { local }(y, x))[y \text { sponsored } x]
\end{aligned}
$$

Personally, I do not find this reading particularly anomalous — certainly nowhere near as bad as the corresponding readings for (36) to (38).

Some readers may worry that a regular appeal to index binding in place of hidden variables will lead to an undesirable proliferation of indices. This is an understandable concern (and one which also gives me some pause), but it should be kept in mind that in many cases, there is good syntactic evidence for hidden pronouns, and this technique would not be used in such cases. It should also be remembered that this technique is being suggested only for contextual parameters which can be manipulated by operators - since the argument against unarticulated constituents based on their bindability is limited to such cases by definition - and not to contextual effects on truth conditions in general (though if Stanley is right, there are no other contextual effects on truth conditions). My own suspicion is that the number of parameters which can be manipulated in this way is relatively small, and limited to general notions like place, time, and perspective; but this is a matter for further investigation. ${ }^{27}$

${ }^{27}$ Given the length of time that has passed since works like Lewis (1981) and Kaplan (1989) first stressed the importance of distinguishing between those contextual parameters which are manipulable by operators and those that aren't, there has been surprising little empirical work done to determine what parameters are in fact manipulated by operators in the languages of the world. The number may be fairly small, but is certainly not minuscule; linguists working on the expression of perspective have frequently emphasized that several different notions of perspective 
5. Conclusion. To account for faultless disagreement over sentences containing predicates of personal taste, I argued for the use of a non-standard individual index as part of a relativist semantic theory, and against various analyses which use a hidden pronoun in place of, or in addition to, the non-standard index. In a theory which distinguishes content from character, using a non-standard index is not semantically equivalent to using a designated variable. Appealing to a hidden pronoun interpreted like an ordinary indexical makes it problematic to account for faultless disagreement between people who do not assume a shared context, as well as cases where someone faultlessly disagrees with a speaker who adopts an exocentric stance. Such an analysis also erroneously predicts that predicates of personal taste should exhibit syntactic crossover effects. Even without a hidden pronoun, it is possible to account for quantified readings by allowing ordinary variable binding operators simultaneously to "bind the index." This technique predicts, as a traditional variable binding analysis does not, that when two predicates of personal taste both appear in the scope of two or more operators, the contextual parameters associated with the predicates will not be bound separately by different operators. In a relativist theory, it may happen that certain inferences are legitimate relative to one person but not another; this is to be expected in an analysis which recognizes some disagreements as authentically faultless. Finally, I suggested that the technique of index binding might be extended to account for bound readings for certain other forms of context sensitivity, which do not give rise to faultless disagreement. Because it allows quantification without the use of syntactically represented hidden variables, the availability of this technique undermines one of the main arguments against "unarticulated constituents."

Versions of this paper were presented at the University of Chicago and at the Arché Pilot Workshop on Contextualism and Relativism. Thanks to the audiences at those talks and to Lenny Clapp for comments.

\section{References}

Barwise, Jon and Cooper, Robin (1981) 'Generalized quantifiers and natural language', Linguistics and Philosophy 4.1.159-219.

Cappelen, Herman and Hawthorne, John (to appear) 'Relativism and monadic truth', Oxford University Press.

Carston, Robyn (1988) 'Implicature, explicature, and truth-theoretic semantics', in Mental representations: The interface between language and reality, 155-181, ed. by Ruth M. Kempson, Cambridge University Press.

may be manipulated more-or-less independently of one another (Oshima 2006; Sells 1987). Even if the number should turn out to be fairly large, however, what is crucial for distinguishing between an index binding analysis and an object language variable binding analysis is whether one has to keep track of an arbitrary number of distinct parameters at once. 
Chomsky, Noam (1981) Lectures on government and binding, Foris Publications.

Egan, Andy, Hawthorne, John, and Weatherson, Brian (2005) 'Epistemic modals in context', in Contextualism in philosophy: Knowledge, meaning and truth, 131-168, ed. by Gerhard Preyer and Georg Peter, Oxford University Press.

Fillmore, Charles (1986) 'Pragmatically controlled zero anaphora', Proceedings from the 12th annual meeting of the Berkeley Linguistics Society, 95-107, ed. by V. Nikiforidou, M. Van Clay, M. Niepokuj, and D. Feder, Berkeley Linguistics Society.

Glanzberg, Michael (2007) 'Context, content, and relativism', Philosophical Studies 136.1-29.

Kaplan, David (1989) 'Demonstratives', in Themes from Kaplan, 481-563, ed. by Joseph Almog, John Perry, and Howard K. Wettstein, Oxford University Press.

Kölbel, Max (2002) Truth without objectivity, Routledge.

Kölbel, Max (2004a) 'Faultless disagreement', Proceedings of the Aristotelian Society 104.53-73.

Kölbel, Max (2004b) 'Indexical relativism versus genuine relativism', International Journal of Philosophical Studies 12.3.297-313.

Lasersohn, Peter (2005) 'Context dependence, disagreement, and predicates of personal taste', Linguistics and Philosophy 28.643-686.

Lasersohn, Peter (to appear) 'Relative truth, speaker commitment and control of implicit arguments', Synthese.

Lewis, David K. (1981) 'Index, context and content', in Philosophy and grammar, 79-101, ed. by Stig Kanger and Sven Ohman, D. Reidel Publishing Co.

MacFarlane, John (2003) 'Future contingents and relative truth', Philosophical Quarterly 53.212.321-336.

MacFarlane, John (2005a) 'Making sense of relative truth', Proceedings of the Aristotelian Society 104.53-73.

MacFarlane, John (2005b) 'The assessment sensitivity of knowledge attributions', in Oxford studies in epistemology, 197-233, ed. by Tamar Szabó Gendler and John Hawthorne, Oxford University Press.

MacFarlane, John (2007a) 'Relativism and disagreement', Philosophical Studies 132.17-31.

MacFarlane, John (2007b) 'Semantic minimalism and nonindexical contextualism', in Contextsensitivity and semantic minimalism: New essays on semantics and pragmatics, 240-250, ed. by Gerhard Preyer and Georg Peter, Oxford University Press. 
MacFarlane, John (to appear a) 'Epistemic modals are assessment-sensitive', in Epistemic modality, ed. by Brian Weatherson and Andy Egan, Oxford University Press.

MacFarlane, John (to appear b) 'Non-indexical contextualism', Synthese.

Oshima, David (2006) Perspectives in reported discourse, Stanford University dissertation.

Pagin, Peter (2005) 'Compositionality and context', in Contextualism in philosophy: Knowledge, meaning and truth, 303-348, ed. by Gerhard Preyer and Georg Peter, Oxford University Press.

Predelli, Stefano (2005) Contexts: Meaning, truth and the use of language, Clarendon Press.

Recanati, François (2002) 'Unarticulated constituents', Linguistics and Philosophy 25.299-345.

Richard, Mark (2004) 'Contextualism and relativism', Philosophical Studies 119.215-242.

Sells, Peter (1987) 'Binding resumptive pronouns', Linguistics and Philosophy 10.3.261-298.

Stalnaker, Robert (1979) 'Assertion', in Pragmatics, 315-332, ed. by Peter Cole, Academic Press.

Stanley, Jason (2000) 'Context and logical form', Linguistics and Philosophy 23.4.391-434.

Stanley, Jason (2005) 'Semantics in context', in Contextualism in philosophy: knowledge, meaning, and truth, 221-254, ed. by Gerhard Preyer and Georg Peter, Oxford University Press.

Stephenson, Tamina (2007) Towards a theory of subjective meaning, MIT dissertation.

Stephenson, Tamina (to appear) 'Relativism and the de se interpretation of PRO', Proceedings of the North East Linguistic Society 38.

Stojanovic, Isidora (2007) 'Talking about taste: Disagreement, implicit arguments, and relative truth', Ms., Institut Jean Nicod. 